Dokuz Eylül Üniversitesi-Mühendislik Fakültesi Fen ve Mühendislik Dergisi

Cilt 20, Sayı 58, Ocak, 2018
Dokuz Eylul University-Faculty of Engineering Journal of Science and Engineering Volume 20, Issue 58, January, 2018

DOI: $10.21205 /$ deufmd. 2018205815

\title{
Beyin Tümörü Tespitinde Görüntü Bölütleme Yöntemlerine Ait Başarımların Karşılaştırılması ve Analizi
}

\author{
Faruk BULUT ${ }^{* 1}$, Illker KILIÇ², İbrahim Furkan INCE ${ }^{3}$ \\ ${ }^{1}$ İstanbul Rumeli Üniversitesi, Mühendislik-Mimarlık Fakültesi, Bilgisayar \\ Mühendisliği Bölümü, 34570, İstanbul (ORCID: 0000-0003-1646-0266) \\ ${ }^{2}$ TIM-TEB Girişim Evi, Ar-Ge Projeleri, 35220, İzmir (ORCID: 0000-0003-0964-5684) \\ ${ }^{3}$ Kyungsung Üniversitesi, Elektrik-Elektronik Mühendisliği Bölümü, Busan, Güney \\ Kore (ORCID: 0000-0003-1570-875X)
}

(Alınıș / Received: 27.05.2017, Kabul / Accepted: 16.11.2017, Online Yayınlanma / Published Online: 20.01.2018)

\begin{abstract}
Anahtar Kelimeler Özet: Görüntü işleme teknikleri klinik karar destek sistemlerinde Markov Random Field,

Tümör,

Görüntü

Segmentasyonu, KKDS (KKDS) sıklıkla kullanılmaktadır. Bu çalışmada çağın önemli bir hastalığı olan beyin tümörlerinin görüntü işleme teknikleri ile tespit edilebilmesi amaçlanmıştır. Manyetik Rezonans görüntülerinden (MRI) yararlanarak beyin tümörünün görüntü segmentasyonu ile tespit edilmesine yönelik bir çalışma gerçekleștirilmiștir. Devlet hastanelerinden MR görüntüleri resmi izinlerle alınmış ve çalışmada kullanılmıştır. Markov Random Field (MRF), Kapur, Kittler ve Otsu algoritmaları ile MR görüntülerindeki tümörlü bölgeler tespit edilmeye çalışılmıştır. Algoritmalar, MR görüntülerinin daha önceden belirlenmiş bölgelerine (ROI - Region of Interest) ayrı ayrı uygulanmıştır. Yapılan deneysel uygulamada Markov Random Field (MRF) algoritmasının beyin tümörü tespitinde diğer algoritmalara oranla daha başarılı sonuçlar verdiği gözlemlenmiștir.
\end{abstract}

\section{Comparison and Performance Analysis of Image Segmentation Algorithms on Brain Tumor Detection}

\begin{tabular}{l}
\hline Keywords \\
Markov Random \\
Field, \\
Brain tumor, \\
Image \\
segmentation, \\
CDSS
\end{tabular}

\begin{abstract}
Image processing techniques in Clinical Decision Support System (CDSS) are often used. In this study, image processing techniques are used in order to detect a common disease, brain tumor. Brain tumors in magnetic resonance images (MRI) are detected by using image segmentation algorithms. MR images have been taken from state hospitals with official permissions in order to use in the study. Brain tumors in MR images are tried to be detected through the Markov Random Field (MRF), Kapur, Kittler and Otsu algorithms. Algorithms were tested on the specific regions (ROI - Region of Interest) of MR images, separately. In experimental applications, Markov Random Field (MRF) algorithm has given more accurate results than the other algorithms.
\end{abstract}




\section{Giris}

Kafatası içerisinde farklı nedenlerle ortaya çıkan ve hızla gelişen beyin tümörü hastalığının tespiti ve tedavisi oldukça zordur. Erken teşhis tedaviyi kolaylaştırmaktadır. Beyin tümörünün kafatası gibi sinırlı bir alanda hızlı büyümesi erken tanı sistemlerini daha da önemli kılmaktadır [1].

Beyin tümörü, bulunduğu yere, tipine ve büyüklüğüne bağlı olarak hastada farklı semptomların oluşmasina neden olmaktadır. Beyin tümörü bulunan hastaların büyük bir bölümü baș ağrısından yakınır [2]. Ancak bu hastalığın tespiti için beyin MR'ının çekilmesi ve sağlık personeli tarafından incelenerek tanının yapılması şarttır.

Bilgisayarla görü ve görüntü ișleme alanında MR görüntülerinde bulunan tümör tespiti ile ilgili birçok bilimsel çalışma yapılmıştır. Örneğin 2013 yılında Bauer ve arkadaşları [3] ile Gordillo ve arkadaşları [4] tarafından yapılan iki farklı çalışmada o yıla dek beyin tümörünün MRI görüntüleri ile tespit edilmesine yönelik yapılan bilimsel çalışmalar incelenmiştir. Özellikle Bauer ekibi tarafından yapılan çalışmada tümör çeşitleri ve 2 ve 3 boyutlu görüntülerdeki yansıma türleri incelenmiş ve bu türlerin klinik karar destek sistemi ile nasıl tespit edilmesi gerektiği belirlenmiştir. Tümör tespitinde kullanılacak özellik seçimi, bölütleme ve sınıflandırma yöntemleri açısından yeni gelișmelere yer verilmiștir. Ayrıca çok modlu görüntülerde doku özelliklerinin yoğunluk veya şekil özelliklerine göre diğerleri ile klyaslandığında avantajlı olduğunu belirtmişlerdir. Her iki araştırmada da, bu alanda yapılan çalışmalar sınıflandırılmış ve aralarındaki farklılıklar ortaya konuşmuştur. Ayrıca yapılan tümör tespitlerinde elde edilen sonuçların doğruluğu hususunda bilimsel çalıșmalarda kullanılan ölçütler sıralanmıştır.

Literatürde beyin tümörünün tespiti üzerine değişik çalışmalar yapılmıștır. Görüntü segmentasyonu yöntemleri, yarı denetimli ve denetimli öğrenme algoritmaları kullanarak MR görüntülerinden tümör tespitinin yapılmıştır [5].

Gajanayake ve arkadaşları tarafından 2009 yılında yapılan bir çalışmada var olan birçok bölütleme metodu analiz edilmiş ve başarım değerlendirmesi yapılmıştır [6]. Yapılan deneysel uygulamalarda, en başarılıdan en az başarılıya doğru sıralama şu şekilde elde edilmiştir: Otsu, Mean Shift, K-means, Fuzzy C-means, Expectation maximization, Discrete Topological Derivative, Continuum Topological Derivative, Iterative thresholding, Two Seed Region Growing ve One Seed Region Growing.

Kurat ve Özkaya 2014 yılında sundukları çalışmada [7], beyin MR görüntüsünden, beyin tümörlerinin yer, boyut ve sinır bilgilerinin hassas bir șekilde ve otomatik olarak elde edilebilmesi sağlamaya çalışmışlardır. Melez Bölgesel Temelli Kenar Hesaplama Algoritması (Hybrid Geodesic Region Based Curve Evolutions for Image Segmentation) yarı otomatik olarak sisteme adapte edilmiş ve temin edilen MR görüntülerinde $\% 70$ başarı elde ediklerini göstermişlerdir.

Havaei ve arkadaşları tarafından yapılan 2017 yılına ait bir çalışmada [8] Derin Sinir Ağları (DNN, Deep Neural Networks) kullanarak yeni bir mimari kullanarak tespit çalışmaları yapmış ve 2013 BRATS veri seti üzerinde başarılı sonuçlar elde etmişlerdir. Önerilen yöntemde tümörün şekli, boyutu ve görüntü özellikleri 
dikkate alınmaksızın otomatik bir yöntem geliştirdikleri belirtilmiştir.

Otsu tekniğinin optimize edilmesi ile ilgili bazı teorik çalışmalar yapılmıştır [9]. 2015 yılında Zhou ve arkadaşları tarafından yapılan bir çalışmada yüksek çözünürlüklü ve 2 boyutlu MR görüntülerinde Otsu ve Ateşböceği (Firefly) optimizasyon algoritmaları ile bölütleme işlemi yapılmak istenmiștir [10]. Hesaplama zamanı olarak daha kısa zamanda doğru bölütleme yapıldığı söylenmektedir.

2016 yılında Prema ve arkadaşları tarafından yapılan bir çalışmada beyin hücrelerinde bulunan kanser hücrelerinin Otsu algoritması ile tespit edilmesine yönelik bir çalışma gerçekleştirmişlerdir [11]. Bu çalışmada görüntü ayrıștırma için Otsu'nun eşikleme değeri ve Watershed segmentasyon yöntemi CT (Computed Tomography) görüntüleri üzerine uygulanmıştır. Bu yazının temel amacı, kanserin yüzdesel dağılımını azaltmak ve hastalı evrelerinin sınıflandırılması için dijital görüntü işleme yöntemini kullanarak beyin nodülü segmentasyonu ve özellik çıkarımı uygulamaktır.

Minimum Hata Eşiklemesi (Minimum error thresholding) olarak da isimlendirilen Kittler yöntemi, temel olarak gri renk sakalası üzerinde çalışmaktadır. Fakat mevcut eşik algoritmaları, gürültülü gri tonlamalı görüntüler için verimli çalışmadığı bilinmektedir. 3D-MET (Three Dimensional Minimum Error Thresholding) yöntemi 2014 yılında Liu ve arkadaşları tarafından 3 boyutlu görüntülerin bölümlenmesi için önerilmiştir ve gri tonlamalarda daha başarılı olduğu iddia edilmektedir [12]. Önerilen 3D-MET yaklaşımında, göreceli entropi teorisine ve 3D histograma dayalı optimal bir eşik ayırımı ile uygulanmaktadır. Histogram, piksellerin gri dağılım bilgilerinden ve bir görüntüdeki komşu piksellerin ilgili bilgilerinden olușur. Ayrica, 3D-MET'in zaman karmașıklığını azaltmak için hızlı bir özyinelemeli yöntem önerilmektedir; burada, gri seviyeler söz konusudur. Deneysel sonuçlar, önerilen yaklaşımın gri görüntü parçalanması için diğer yöntemlere kıyasla üstün segmentasyon performansı sağlayabileceğini göstermektedir.

Bhandari ve arkadaşları 2014 yılında, Cuckoo arama algoritması ve Wind Driven Optimization (WDO) yöntemi ile çok seviyeli bölütle (CS) me işlemini Kapur Entropi yöntemi kullanarak gerçekleştirmişlerdir [13]. Bu çalışmada, fitness fonksiyonu olarak en iyi çözüm, CS ve WDO algoritması ile Kapur'un optimum çok seviyeli eşikleme entropisi kullanılarak elde edilmiştir. En uygun eșik değerinin seçimi için yeni bir CS ve WDO algoritması yaklaşımı kullanılmıştır. Bu teknikte, ilk rasgele eşik değerlerinden en iyi çözümü veya en iyi uygunluk değerini elde edebilmek için korelasyon fonksiyonu kullanılmıştır. Geliştirdikleri yöntemi bir dizi uydu görüntülerine uygulayarak başarılı sonuçlar elde ettiklerini belirtmişlerdir.

Son yıllarda başarılı bir segmentasyon algoritması olan MRF tekniği değişik sağlık alanlarında kullanıldığg görülmektedir. Görüntüsü çekilen beyaz lezyonlar (ölü beyin hücreleri), kontrast iyileştirilmesi ile birlikte MRF tekniği ile segmente edilmiștir [14]. Yapılan kıyaslamalarda kullanılan tekniğin diğer yöntemlere göre daha başarılı sonuç verdiği ispat edilmiştir. Son ylllarda yapılan başka bir çalışmada MR görüntülerinden nöron etkileşimlerinin segmentasyonu yine MRF tekniği kullanılarak elde edilmiştir. Bu çalışmada ayrıca çizge tabanlı (graph based) otomatik ayrışım yapan metotlar kullanılmıştır. Aynı şekilde başka bir çalışmada ultrason görüntülerinde 
F. Bulut, İ. Kılıç, İ.F. İnce / Beyin Tümörü Tespitinde Görüntü Bölütleme Yöntemlerine Ait Başarımların Karşılaştırılması ve Analizi

$\begin{array}{llrlrl}\text { birbirine } & \text { benzeyen } & \text { yapların } & \text { farklı dokuların farklı gri seviyelere sahip } \\ \text { mozaiklenmesi de MRF } & \text { tekniği } & \text { olduğu varsayımına dayanır. Bu } \\ \text { kullanılarak başarılı bir } & \text { şekilde } & \begin{array}{l}\text { çalıșmada da aynı yöntem tercih } \\ \text { gerçekleştirilmiştir }[15,16] .\end{array} & & \text { edilmiştir. }\end{array}$

Bu çalışmada MR görüntülerinde var olan beyin tümörünün MRF, Kapur, Kittler ve Otsu gibi dört farklı görüntü ayrıștırma algoritması ile tespit edilmesi amaçlanmıştır. Ayrıca MRF, Kapur, Kittler ve Otsu teknikleri aynı MR görüntülerine uygulanarak performans analizi yapılmıştır.

Makalenin geriye kalan kısmında dört bölüm daha vardır. Takip eden 2 . bölümde çalışmada kullanılan yöntemlerin açıklamasına ve ilgili yöntemlerin performans ölçümleri için kullanılan metriklere yer verilmiştir. 3 . bölümde ise deneysel çalışmalardan elde edilen sonuçlara ve son bölümde ise tartışma ve sonuçlara yer verilmiştir.

\section{Bölütleme Metotları ve Performans Ölçütleri}

Çalışmada, tümör tespiti ile ilgili yöntem 4 ana aşamadan oluşmaktadır:

1. Așama, ilk olarak görüntünün kullanıma hazır hale getirilmesidir (Image pre-processing). Bu aşamada gereksiz kısımlar kırpılmakta, belirli bir kontrast aralığında olması sağlanmakta, yoğunluk normalize edilmekte ve gürültü oluşturan bölgeler temizlenmektedir.

2. Așama, beyin tümörlerinin bölütlenmesidir (Segmentation of brain tumor images). Bölütleme için kullanılan özellikler büyük oranda tümör türüne ve sınıfına bağlıdır, çünkü farklı tümör tipleri ve sınıfları görünüşte çok farklılık gösterebilir (ör. Kontrast alım, şekil, düzenlilik, yer, vb.). Ek olarak, özellik seçimi (feature extraction) aynı zamanda segmente edilecek olan tümörün alt bölmesine de bağlı olacaktır. Beyin tümörü parçalanması için kullanılan en yaygın özellik görüntü yoğunluğudur. $\mathrm{Bu}$,

3. Aşama, bölütleme yani segmentasyon algoritmalarının uygulanmasıdır. Bölütleme ișleminde temelde iki farklı yöntem karşımıza çıkmaktadır. Bunlar bölge ve kenar tabanlı tümör analiz yöntemleridir. Bölütleme işlemlerinde sinıflandırma ve kümeleme alanında farklı algoritmalar da tercih edilebilmektedir. $\mathrm{Bu}$ çalışmada bölge tabanlı yöntemler tercih edilmiştir.

4. Așama, tümör alglama algoritmalarının doğruluğunun tespitidir. Segmentasyon algoritmaları burada aynı zamanda tümör algılama amacıyla da kullanılmıştır. Normalde bölütleme işlemi farklı yoğunluklardaki bölgelerin analizi için kullanılırken burada, tümörün var olup olmadığına karar vermeye ve tümör lokasyonunu çıkarma amacıyla kullanılmıştır.

Görüntü segmentasyonu örüntü tanıma, makine öğrenmesi ve tıbbi görüntü işleme alanlarında sıklıkla kullanılmaktadır. Görüntü ayrıştırma teknikleri, genelde MR görüntülerinin gri tondaki histogram bilgilerini kullanır. RGB formatındaki renkli MR görüntüleri $[0,255]$ aralığındaki gri tonlara (Gray Scale) dönüştürülerek kullanılır.

Genellikle MR görüntülerinde bulunan tümör bölgesi arka plana göre oldukça küçük bir orana sahiptir. Bu durum tümörün tespitini zorlaștırmaktadır. $\mathrm{Bu}$ amaçla ROI (Region of Interest) ile olası tümör bölgesi konveks bir alan içerisine alınarak inceleme yapılmıştır. Uygulamalarda genellikle dikdörtgenden daha çok konkav olmayan çok gen bölge manüel olarak belirlenir. Bu sayede ROI bölgesinin dışında kalan bölge göz ardı edileceği için daha yüksek başarı elde edilmesi sağlanacaktır. 
Dört farklı görüntü ayrıștırma tekniğinin açılklamaları aşağıda verilmiştir.

\subsection{Otsu}

İlk olarak Nobuyuli Otsu tarafindan 1979 yllında önerilmiştir [17]. Histogram tabanlı bir eşikleme yöntemi olan Otsu algoritması; histogramda eşikleme yapilabilecek en uygun konumun bulunması için kullanılır. Otsu yönteminde sınıflar arasındaki varyans temel alınır. Kümeleme tabanlı bir eşikleme metodudur. Otsu metodu, sayısal görüntüyü ön ve arka plan olmak üzere iki nesneden oluştuğunu kabul eder. Her bir sınıfın varyans değerini hesaplar. Optimum gri eşik değeri ise, görüntüdeki nesnelere ait ağırlıklı sınıflar arası varyans değerinin minimizasyonu ile bulunur. $\mathrm{Bu}$ metodun nesnelere ait piksel sayıları eğer birbirine yakın ise çok başarılı olduğu görülmüştür [18]. Ağırlıklı sınıflar arası varyans şu şekilde bulunur:

$$
\begin{gathered}
V= \\
\frac{\mathrm{P}(\mathrm{T})[1-\mathrm{P}(\mathrm{T})]\left[\mathrm{m}_{\text {ön }}(\mathrm{T})-\mathrm{m}_{\text {arka }}(\mathrm{T})\right]^{2}}{\mathrm{P}(\mathrm{T}) \sigma_{\text {ön }}^{2}(\mathrm{~T})+[1-\mathrm{P}(\mathrm{T})] \sigma_{\text {arka }}^{2}(\mathrm{~T})}
\end{gathered}
$$

Varyans V, standart sapmanın kareköküdür. Burada mön ve marka sırasıyla resimdeki ön ve arka nesneye ait sinıflar arası varyans değerini göstermektedir. $\sigma_{\text {ön }}$ ve $\sigma_{\text {arka }}$ ise resimdeki sadece ön ve arka nesneye ait varyans değerlerini gösterir. T ise $[0,255]$ gri renk aralı̆̆ında rasgele seçilen bir eşik değeridir. $P(T)$, ilgili gri seviyenin resimde bulunma olasılı̆̆ını gösterir.

\subsection{Kapur}

Kapur yönteminde, gri seviyeli histogramın entropisi esas alınmaktadır. Sinıflar arası entropi değerleri dikkate alınarak en uygun eşik değeri tespit edilir. Entropi tabanlı bir görüntü eşikleme metodudur [19]. Kapur metodu; sayısal görüntüyü ön plan ve arka plan olmak üzere iki nesne şeklinde ele alır. 0 siyah, 255 ise beyaz olmak üzere her bir gri seviye için nesnelerin entropisini alıp toplamını hesaplar. Her iki nesneye ait toplam entropinin maksimum noktaya ulaştığı gri seviyeye Kapur eşik değeri adı verilir. Resim, bulunan Kapur eşik değerinden iki farklı nesneye ayrıştırılabilir. Toplam entropi $\left(\mathrm{E}_{\text {ön }}+\right.$ Earka) şu șekilde bulunur:

$$
\begin{gathered}
E=-\sum_{\mathrm{g}=0}^{\mathrm{T}} \frac{\mathrm{P}(\mathrm{g})}{\mathrm{P}(\mathrm{T})} \log \frac{\mathrm{P}(\mathrm{g})}{\mathrm{P}(\mathrm{T})} \\
-\sum_{\mathrm{g}=\mathrm{T}+1}^{\mathrm{P}(\mathrm{T})} \log \frac{\mathrm{P}(\mathrm{g})}{\mathrm{P}(\mathrm{T})}
\end{gathered}
$$

Burada g $[0,255]$ aralığındaki gri seviyeyi, G görüntü içerisindeki maksimum gri seviye değerini gösterir.

\subsection{Kittler}

Kittler ve Illingworth tarafindan 1986 yılında geliştirilmiş kümeleme tabanlı bir eşikleme metodudur [20]. Literatürdeki çoğu eşikleme metotlarının aksine Kittler sayısal görüntüye ait iki nesnenin birbirinden çok farklı standart sapma ve varyans değerlerine sahip olabileceğini kabul etmiş ve birer Gauss eğrisi olarak düşünülmesi gerektiğini dile getirmiştir. Dolayısı ile eşikleme problemini bir Gauss eğrisine uydurma problemine dönüştürmüştür.

$$
\begin{gathered}
\mathrm{P}_{\mathrm{i}}(\mathrm{T})=\sum_{\mathrm{g}=\mathrm{a}}^{\mathrm{b}} \mathrm{h}(\mathrm{g}) \\
\mu_{i}(\mathrm{~T})=\frac{1}{P_{i}(T)} \sum_{\mathrm{g}=\mathrm{a}}^{\mathrm{b}} \mathrm{g} \cdot \mathrm{h}(\mathrm{g}) \\
\sigma_{i}^{2}(T)= \\
\frac{1}{P_{i}(T)} \sum_{\mathrm{g}=\mathrm{a}}^{\mathrm{b}}\left(\mathrm{g}-\mu_{\mathrm{i}}(\mathrm{T})\right)^{2} \cdot \mathrm{h}(\mathrm{g})
\end{gathered}
$$

Bayesian sınıflama kuralına dayanarak kendi geliştirdiği bir Bayes fonksiyonu ile eşik değerini tespit etmiştir.

Burada a ve b şu şekildedir: 
F. Bulut, İ. Kılıç, İ.F. İnce / Beyin Tümörü Tespitinde Görüntü Bölütleme Yöntemlerine Ait Başarımların Karșlaștırılması ve Analizi

$$
\begin{gathered}
a=\left\{\begin{array}{l}
0, \quad i=1 \\
T+1, \quad i=2
\end{array}\right\} \\
b=\left\{\begin{array}{l}
T, \quad i=1 \\
n, \quad i=2
\end{array}\right\}
\end{gathered}
$$

Bayes Fonksiyonu ise 6 numaralı formülde tanımlanmaktadır.

$$
\begin{aligned}
& f=1+2 \times\left[\mathrm{P}_{\text {ön }}(\mathrm{T}) \times \log \sigma_{\text {ön }}(\mathrm{T})+\right. \\
& \left.\mathrm{P}_{\text {arka}}(\mathrm{T}) \times \log \sigma_{\text {arka }}(\mathrm{T})\right]-2 \times\left[\mathrm{P}_{\text {ön }}(\mathrm{T})\right. \\
& \left.\times \log \mathrm{P}_{\text {ön }}(\mathrm{T})+\mathrm{P}_{\text {arka }}(\mathrm{T}) \times \log \mathrm{P}_{\text {arka }}(\mathrm{T})\right]
\end{aligned}
$$

Burada $\mathrm{P}_{\text {ön }}(\mathrm{T})$ ve $\mathrm{P}_{\text {arka }}(\mathrm{T})$ ön ve arka plan nesnelerinde $\mathrm{T}$ gri değerine sahip piksel

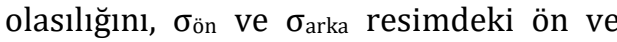
arka nesneye ait varyans değerlerini göstermektedir.

\subsection{Markov Random Field (MRF)}

Olasılık tabanlı MRF algoritması görüntüdeki pikselleri dağılım fonksiyonlarına göre etiketle yapar [21]. $M \times N^{\prime}$ lik bir $S$ matrisinde pikseller indekslenir ve hedef bölgesi belirlenir. $S$ için tanımlanmış komşu sistemi $N=$ $\left\{N_{i} \mid \forall_{i} \in S\right\}$ olacak şekilde tanımlanır.

$N_{i}, i^{\prime}$ ye komşu piksel setidir. Bu çalışmada üzerinde çalışılan merkez pikselin etrafındaki 8'li komșuluk sistemi kullanılmıştır Şekil 1'de görüldüğü gibi kullanılmıştır.

\begin{tabular}{|l|l|l|}
\hline 1 & 2 & 3 \\
\hline 4 & $\boldsymbol{i}$ & 5 \\
\hline 6 & 7 & 8 \\
\hline
\end{tabular}

Şekil 1. i'ye komşu 8 adet piksel.

Clique $(c \in C)$ ise birbirine komșu olan noktalar bütünüdür $\left(\forall i i^{\prime} \in c, i \in N_{i^{\prime}}\right)$ şeklinde tanımlanır. Yatay, dikey ve diyagonal clique'ler uygulamada kullanılmıştır. MxN'lik matriste tüm pikseller ait olduğu nesneye etiketlenir. $L=\{1,2, \ldots, k\}$ nesne olarak varsayılırsa, bu seneryoda $\mathrm{k}=2$ olur ( 0 görüntüyü; 1 arka planı temsil eder). Eğer S'yi etiketlerken rastgele değişken $X$ alınırsa, $X_{S} \in L$ formülü $\mathrm{S}$ pikselindeki $X^{\prime}$ lerin enerji değerini verir. Hammersley - Clifford teoremine göre, $X^{\prime}$ in enerji yoğunluğu aşağıdaki Gibbs yoğunluğu ile verilir:

$$
\begin{gathered}
p(x)=Z^{-1} \cdot e^{-\frac{1}{T} U(x)} \\
Z=\sum_{x \in S} e^{-\frac{1}{T} U(x)}
\end{gathered}
$$

T, MRF'de azaltılacak olan sicaklık katsayısı olup aksi belirtilmedikçe 1 olarak alınır. 8 komșunun ortasındaki pikselin enerjisi $U(x)$ ile şu şekilde bulunur:

$$
U(x)=\sum_{c \in C} V(x)
$$

Merkez piksele ait Clique enerjisi $\mathrm{V}(\mathrm{x})$ aşağıdaki formüldeki gibi olup 8 komşuya ait Clique enerjilerinin toplamı bulunarak hesaplanır.

$$
\begin{aligned}
& V(x) \\
& =\left\{\begin{array}{l}
-\beta \text { if } x_{s}=x_{r} \text { with } s, r \in C \\
\beta \text { if } x_{s} \neq x_{r} \text { with } s, r \in C
\end{array}\right.
\end{aligned}
$$

Bir piksele ait toplam enerji 2 farklı enerjinin toplamı ile bulunabilir. Bunlardan birincisi; pikselin ait olduğu nesnenin ortalama ve standart sapmasını içeren Gauss dağılım formülünün logaritmasıdır. İkincisi ise merkez pikselin 8 komşusuna ait koşullu olasılıktır. $\mathrm{Bu}$ şekilde her bir pikselin tümör veya arka plana ait olma olasılığına göre iki farklı enerji durumu hesaplanmış olur. MRF yöntemi çalışırken her bir çevrimde ilgili pikselin sınıfı yukarıda bahsedilen iki enerjiden büyük olanın sınıfı ile değiştirilir. İterasyonlar piksellerin sınıfları değişmeyinceye kadar devam ettirilir. Nihai sinıflama sonucu beyin tümörü ve arka planı birbirinden ayırt etmiş olur. $\mathrm{Bu}$ çalışmada hem tümörün hem de beyine ait piksellerin 
dağılımı Gauss ile hesaplanmıştır. Hesaplamada ortalama $(\mu)$ ve standart sapma $(\sigma)$ kullanılmıştır.

\subsection{Performans Ölçüm Metrikleri}

Şekil 2'de görüldüğü üzere segmentasyon işlemi sonrası elde edilebilecek histogram grafiğinde, ayrıștırılmak istenen görüntü tümör ve arka plan olarak iki gruba ayrilır [22].

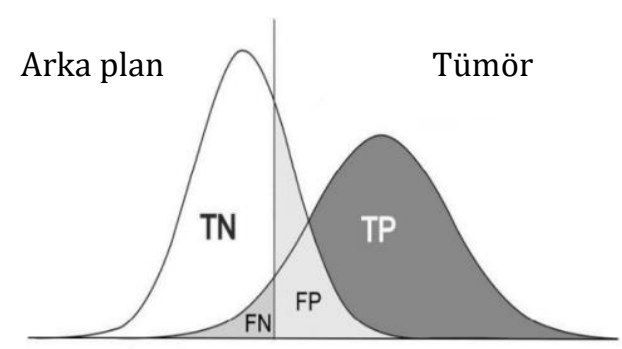

Şekil 2. Görüntü segmentasyonun histogram bazlı başarı durumu

FP (False Positive), FN (False Negative), TP (True Positive) ve TN (True Negative) değerleri ayrıştırma işleminin başarı durumunu göstermektedir. Tümör bölgesine segmentasyon işleminde "Tümör" etiketlemesi yapılırsa sonuç TP, tümör bölgesine "Arka Plan" etiketlemesi yapılırsa FN, arka plana "Tümör" etiketlemesi yapilırsa FP ve son olarak arka plana "arka plan" etiketlemesi yapılırsa TN olur. TP, TN, FP ve FN değerleri piksel sayısını gösterdiği durumlarda ayrıștırma işleminin başarısı yani doğruluk (Accuracy) oranı 11 numaralı formül ile bulunur.

$$
D o g ̆ r u l u k=\frac{T P+T N}{T P+T N+F P+F N}
$$

TP, TN, FP ve FN değerleri Karmaşıklık Matrisi (Confusion Matrix) veya "Hata Matrisi" olarak tanımlanan bir tabloya Tablo 1'de görüldüğü gibi aktarılır. Bu tablo, iki sınıflı bir veri setinde belirli bir sınıflandırıcının belirli bir veri seti üzerinde verdiği tahmin sonuçlarının doğruluğunu barındırır.

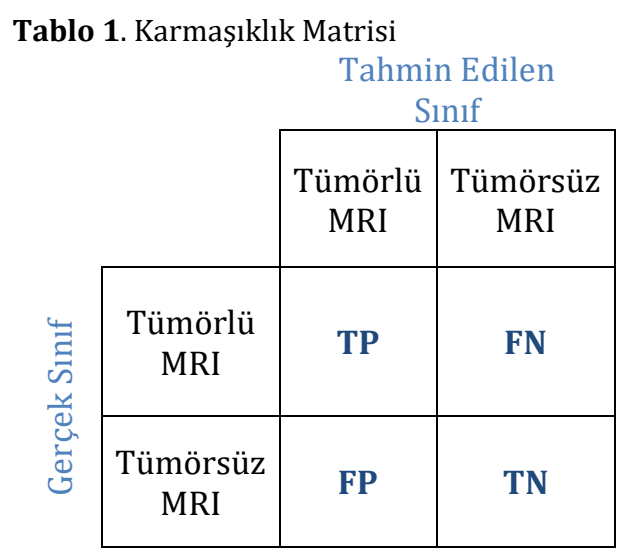

Tablo 1'de görüldüğü üzere Tümörlü MRI ve Tümörsüz MRI iki farklı sınıf türü olarak kabul edilmektedir. TP doğru sınıflandırılmış yani gerçekte var olan tümörün tespit edildiği $M R$ görüntü sayısını vermektedir.

FN sayısı, gerçekte tümörlü olan MR görüntüsünün tümörsüz olarak tespit edildiğini göstermektedir. FP ise tümörsüz MR görüntülerinin tümörlü olarak tahmin edildiğini göstermektedir. Son olarak TN sayısı tümörsüz MR görüntülerinin doğru bir şekilde yani tümörsüz olarak tespit edilesini göstermektedir.

Karmașıklık tablosu kullanılarak 11 numaralı formül ile doğruluk oranı, 12 numaralı formül ile TPR (True Positive Rate) ve 13 numaralı formül ile FPR (False Positive Rate) değerleri elde edilmektedir.

$$
\begin{aligned}
& T P R=\frac{T P}{T P+F N} \\
& F P R=\frac{F P}{F P+T N}
\end{aligned}
$$

$[0,1]$ aralığında değişen TPR ve FPR değerleri, algoritmaların bașarılarını sayısallaştırmak için kullanılmaktadır. Ayrıca TPR ve FPR değerleri, ROC uzayının çizilmesinde de kullanılmaktadır. Gerekli durumlarda Netlik (Precision), Hassasiyet (Recall) ve 
F. Bulut, İ. Kılıç, İ.F. İnce / Beyin Tümörü Tespitinde Görüntü Bölütleme Yöntemlerine Ait Başarımların Karşılaştırılması ve Analizi

F1-Score gibi başarı ölçütleri de bu tablodan yararlanılarak bulunmaktadır.

\subsection{ROC Uzayı}

ROC Eğrisi (Receiver operating characteristic Curve) ve ROC Uzayı (ROC Space) sinıflandırma başarısını ölçmek kullanılan yöntemlerden biridir. ROC uzayı aynı veri seti üzerinde çalıșan farkl algoritmaların başarısını görselleştirmek için kullanılmaktadır ve Şekil 3'deki gibi görselleștirilmektedir. 13 numaralı formülde gösterilen FP oranının yatay eksen, 12 numaralı formülde gösterilen TP oranının ise dikey eksen olduğu görselde, diyagonal çizgi rasgele sınıflandırma başarısını göstermektedir. Sol üst noktaya en yakın sınıflandırıcının en başarılı sınıflandırıcı olarak kabul edilmektedir. Sağ alt nokta ise olabilecek en kötü sınıflandırma başarısını göstermektedir [23].

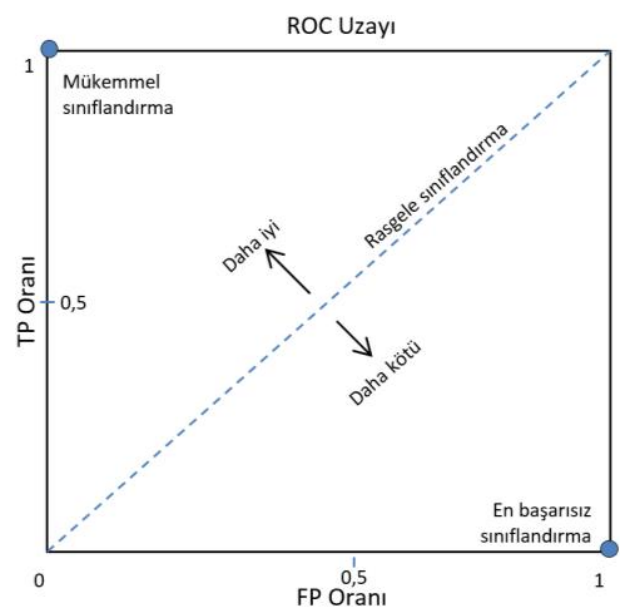

Şekil 3. ROC Uzayının tanımı

\section{Deneysel Sonuçlar}

Deneysel sonuçlar dört farklı eşikleme algoritmasının MATLAB ortaminda uygulanması ile elde edilmiştir. RGB formatındaki görüntüler öncelikle gri tona çevrilmiş ve ardından ROI bölgesi seçilerek algoritmalar uygulanmıştır. Görüntü ayrıştırma sonuçları incelenerek gerçek tümör ile karşılaştırılmış ve metotların başarı durumları değerlendirilmiştir.
3.1. Üç farklı tümör üzerinde yapılan çalışma

3 farklı tümör üzerinde yapılan çalışmalar așağıdaki Şekil 4, 5 ve 6'de gösterilmiştir.

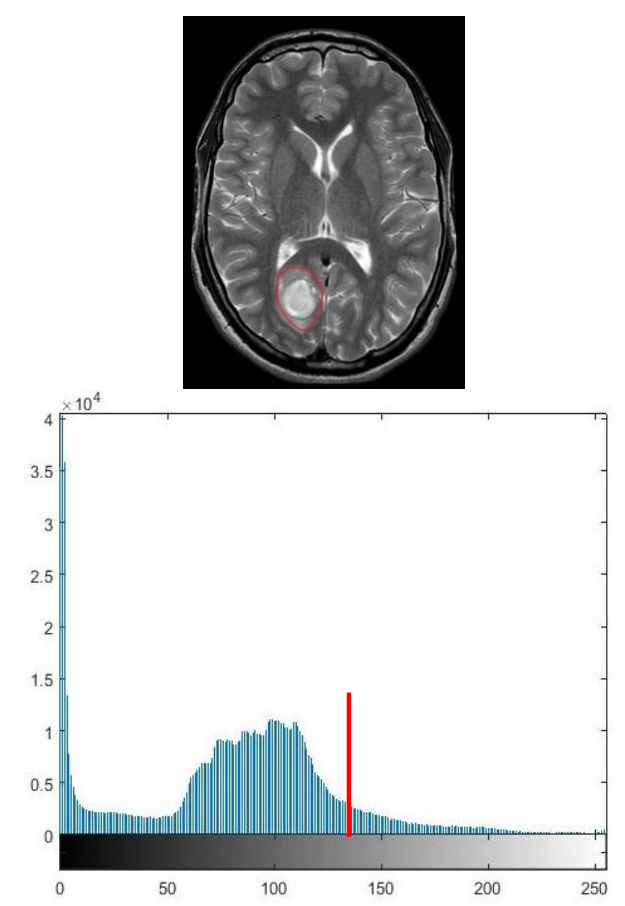

Şekil 4. Birinci beyin tümörüne ait görüntü ve histogram bilgileri

Her bir şeklin sol tarafindaki MR görüntüsü içerisinde var olan tümör kırmızı renk ile çerçeve içerisine alınmıştır. Sağ taraftaki histogram bilgisinde ise arka planı ve tümörü ayıran kırmızı çizgi bulunmaktadır. Histogram grafiğindeki kırmızı ayırıcı çubuğun sağ tarafındaki dağılım tümöre aittir. Sol taraftaki dağılım ise arka plana aittir. Histogram grafiğinde yatay $x$ ekseni gri tonlama aralığını 8 bit değerinde yani $[0,255]$ aralığında göstermektedir. Dikey $y$ ekseni ise her bir gri tondan görüntü içerisinde kaçar adet olduğunu göstermektedir.

Şekil 4'de, tespit edilen bölge ile dört algoritmanın belirlediği bölge tutarsızlık içindedir. Tümörün gri skalasındaki renk değerleri ile arka planın renk değerleri 


\section{Karşılaştırılması ve Analizı}

birbirine yakın olduğu ve tümörün kapladığı alan az olduğu için kesin bir sonuç alınamamıştır. Fakat ROI ile tümör bölgesi seçildiğinde dört algoritma da başarılı sonuçlar vermiştir.

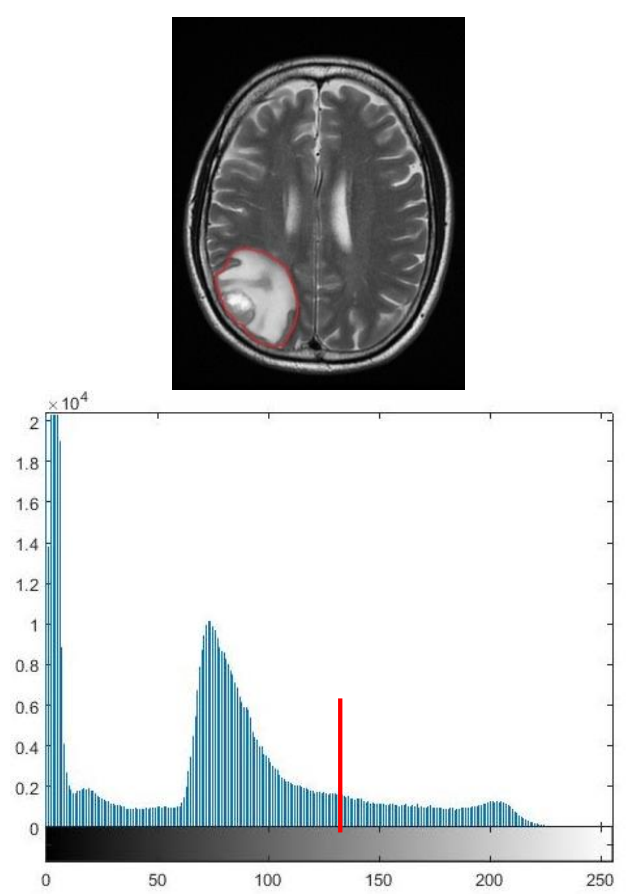

Şekil 5. Birinci beyin tümörüne ait görüntü ve histogram bilgileri

Şekil 5'deki örnekte belirgin bir tümör görüntüsü vardır. Tümörün gri skalasındaki renk değerleri ile arka planın bazı bölgelerindeki renk değerleri benzeşmektedir. Bu nedenle resmin diğer bölgelerinde aynı tonda bulunan görüntüler algoritmalar tarafından tümör olarak algılanmaktadır. Histogram grafiğinde kırmızı çizginin sağ tarafı tümöre aittir. Görüldüğü üzere bir önceki örneğe göre biraz daha belirgin bir dağılım vardır. Bölgesel bazlı çalışmada en başarılı eşiklemeri MRF algoritması vermiştir.

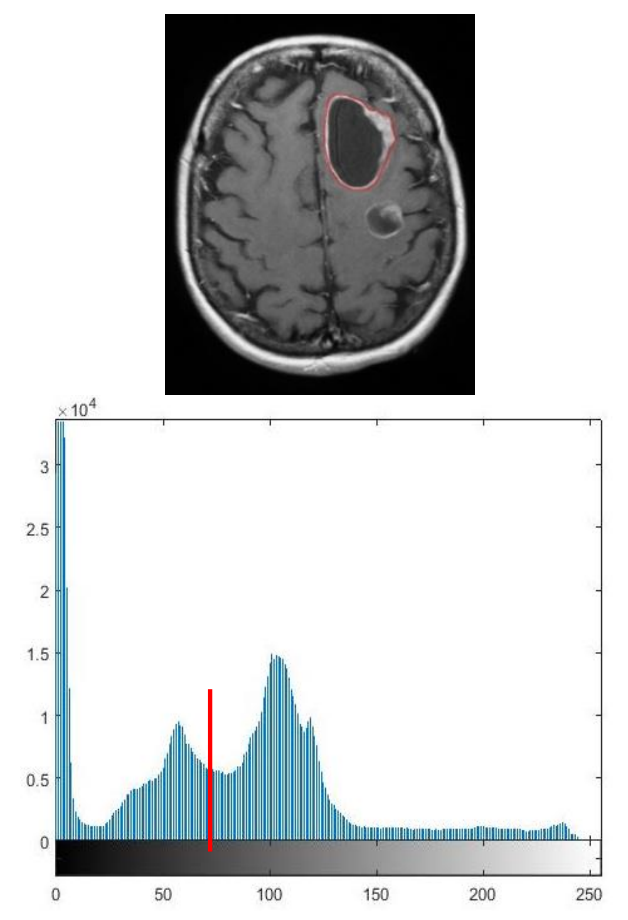

Şekil 6. Birinci beyin tümörüne ait görüntü ve histogram bilgileri

Şekil 6'de ise histogram grafiğindeki kırmızı ayırıcı çubuğun bu sefer sol tarafındaki dağılım tümöre aittir. Diğer dağılımlarla kıyaslandığında burada belirgin bir Gauss dağılımı vardır. Tespit edilen bölge ile MRF, Kapur ve Kittler algoritmalarının belirlediği bölge benzerdir.
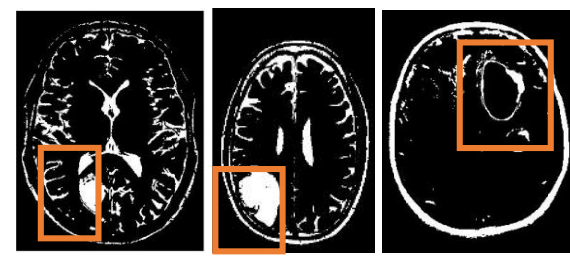

Şekil 7. Beyin tümörlerine ait görüntülerin binary-image görüntüleri ve turuncu renk içerisindeki ROI alanları.

Tüm algoritmalar MR görüntülerine uygulanmıștır. Ancak kafatası, beyinin diğer bölgeleri ve tümör benzer gri skalaya sahip olduğu için algoritmalar genellikle hatalı sonuçlar vermiştir. Şekil 

Karşılaştırılması ve Analizi

7'de gösterildiği gibi ROI ile seçilen bölgede daha başarılı sonuçlar elde edilmiştir. Genel bir sıralama yapıldı̆̆ında elde edilen eşikleme sonuçlarına göre en başarılı algoritma sırasıyla MRF, Kittler, Kapur ve Otsu olmuştur.
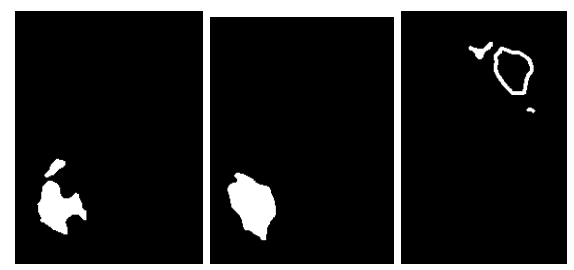

Şekil 8. Beyin tümörlerinin MRF algoritması ile tespit edilmesi

MRF ile elde edilen eşikleme işleminde tümör görüntüleri siyah-beyaz görüntüye dönüştürüldüğünde Şekil 8'da elde edilen sonuçlar ortaya çıkmıştır.

\subsection{Performans Sonuçları}

Deneysel sonuçlar, 23 adet MR görüntüsün dört farklı algoritmada kullanılmasıyla elde edilmiştir. MR görüntüleri Karşıyaka Devlet Hastanesi Beyin ve Sinir Hastalıkları kliniğinden resmi izinlerle alınmıştır. Elde edilen MR görüntülerinden 18 tanesi pozitif (kanser), 5 tanesi de negatif (kanser değil) özelliğindedir. 23 görüntü üzerinde yapılan görüntü ayrıștırma ișleminde ilgili bölgeler ROI ile işaretlenerek 4 farklı algoritmaya uygulanmıștır.

Görüntü ayrıştırma işleminde piksel temelli bir başarım değerlendirmesinin oldukça zor bir iştir. $\mathrm{Bu}$ nedenle çalışmamızda elde edilen 23 adet MR görüntüsü içerisinde tümör olan ve olmayan bölgelerin doğru tespit edilip edilmediği ile ilgili bir bașarım değerlendirmesi yöntemi tercih edilmiştir. $\mathrm{Bu}$ nedenle Karmaşıklık Matrisi tablosunda yararlanılmıştır. Kullanılan her bir algoritma için ayrı ayrı Karmașılklık Matrisi elde edilmiștir.

Tablo 2. Algoritmaların karmaşıklık matrisleri ve genel başarı durumları

\begin{tabular}{|c|c|c|c|c|c|c|c|}
\hline \multicolumn{2}{|c|}{ Otsu } & \multicolumn{2}{|c|}{ Kapur } & \multicolumn{2}{|c|}{ Kittler } & \multicolumn{2}{|c|}{ MRV } \\
\hline $\mathrm{TP}=13$ & $\mathrm{FP}=5$ & $\mathrm{TP}=11$ & $\mathrm{FP}=7$ & $\mathrm{TP}=15$ & $\mathrm{FP}=3$ & $\mathrm{TP}=16$ & $\mathrm{FP}=1$ \\
\hline $\mathrm{FN}=3$ & $\mathrm{TN}=2$ & $\mathrm{FN}=2$ & $\mathrm{TN}=3$ & $\mathrm{FN}=2$ & $\mathrm{TN}=3$ & $\mathrm{FN}=1$ & $\mathrm{TN}=4$ \\
\hline \multicolumn{2}{|c|}{$\mathrm{TPR}=0,722$} & \multicolumn{2}{|c|}{$\mathrm{TPR}=0,611$} & \multicolumn{2}{|c|}{$\mathrm{TPR}=0,833$} & \multicolumn{2}{|c|}{$\mathrm{TPR}=0,944$} \\
\hline \multicolumn{2}{|c|}{$\mathrm{FPR}=0,600$} & \multicolumn{2}{|c|}{$\mathrm{FPR}=0,400$} & \multicolumn{2}{|c|}{$\mathrm{FPR}=0,400$} & \multicolumn{2}{|c|}{$\mathrm{FPR}=0,200$} \\
\hline \multicolumn{2}{|c|}{ Acc $=0,652$} & \multicolumn{2}{|c|}{ Acc $=0,608$} & \multicolumn{2}{|c|}{ Acc $=0,782$} & \multicolumn{2}{|c|}{ Acc $=0,870$} \\
\hline
\end{tabular}

Tablo 2'de sirasiyla Otsu, Kapur, Kittler ve MRV algoritmalarının 23 adet MR görüntüsünden elde edilmiş deneysel sonuçları vardır. Her bir teknik için Karmaşıılık Matrisi, TPR ve FPR değerleri bulunmuştur. Bilindiği üzere TPR, doğru bir şekilde etiketlenen tümörlü görüntü sayısının tümörlü olarak etiketlenen görüntüler içindeki oranını göstermektedir. FPR ise, gerçekte tümörlü olan fakat tümörsüz olarak işaretlenmiş olan MR görüntülerinin tümörsüz olarak işaretlenenler İçindeki oranını göstermektedir.

Tablo 2'de de görüldüğü üzere sadece doğruluk (Acc) kriteri ile en başarılıdan 
en başarısıza doğru algoritmalar sıralanacak olsa \%87'lik başarı ile MRV birinci olurdu. Diğerleri ise sırasıyla $\% 78,2$ ile Kittler, \%60,8 ile Kapur ve $\% 65,2$ ile Otsu olurdu.

\subsection{ROC Uzayı Sonucu}

Tablo 2'den yararlanarak her bir algoritma için elde edilen deneysel sonuçlara ait TPR ve FPR performans değerleri Şekil 9'de görüldüğü gibi görselleştirilmiştir. $\mathrm{Bu}$ durumda en bașarılı ayrıștırma ișlemini yapan algoritmanın MRV olduğu görülmektedir. $1 \times 1$ 'lik tablonun sol üst köşesine olan yakınlık durumuna göre yapılan en bașarılı algoritma sıralaması MRV, Kittler, Kapur ve Otsu șeklindedir. Bilindiği üzere sol üst köșeye en yakın olan en başarılı nokta en başarılı olarak kabul edilmektedir.

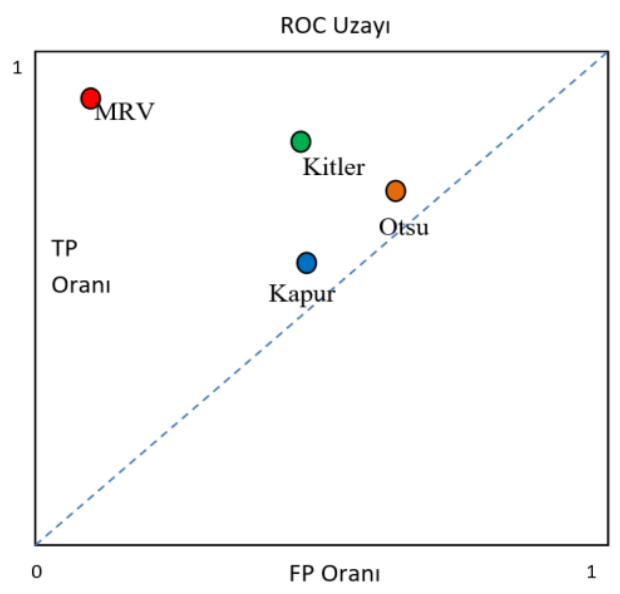

Şekil 9. Segmentasyon algoritmaların başarılarının ROC Uzayında gösterimi

Bu bölümde duyarlık (precision), anma (recall) ve F1-skoru (duyarlık ve anma ölçütlerinin harmonik ortalaması) değerleri ile ilgili hesaplamalar yapılmıştır. Söz konusu değerlerin yanı sıra belirginlik (specificity) ve Jaccard benzerlik değeri gibi diğer başarım ölçütleri de elde edilerek makalede verilebilir. Fakat burada kullanılan performans ölçütlerinin yeterli olduğu düşünülmektedir.
Görüldüğü üzere bu çalışmada sadece tümör "var" veya "yok" durumlarına göre tespit durumları oluşturulmuștur. Sonraki çalışmalarda piksel alan büyüklükleri üzerinden uzman doktor tarafından işaretlenmiş referans veri (ground-truth) ile orijinal görüntüden elde edilen algoritmik sonucu kıyaslamaya dayanan bir başarım değerlendirmesi yapılabilir. $\mathrm{Bu}$ karşılaștırma orijinal görüntüden elde edilen ile referans veride tümör olarak işaretlenmiş alanların örtüşme oranlarını temel alarak karşılaştırılabilir.

\section{Tartışma ve Sonuç}

Projede, çağın en önemli hastalıklarından biri olan beyin tümörü üzerine bir çalışma gerçekleștirilmiştir. Çalışma, hastanelerdeki doktorların tümör tespiti ile ilgili verecekleri karara destek niteliğindedir. Bilindiği üzere hastalık tespitinde en son karar doktorlara aittir. Ancak yapılan projede doktorların yanılma paylarını en aza indirmek amaçlanmıștır. $\mathrm{Bu}$ nedenle farklı anomali durumlar göz önüne alınarak en iyi tespit sistemini elde edebilmek için çalışma detaylandırılmıştır.

Öncelikle kısıtlı imkânlara rağmen devlet hastanelerinden MR görüntülerini elde edebilmek için resmi izinler alınmıștır. Tümör içeren ve içermeyen 23 adet MR görüntüsünün doğru bir şekilde tespit edilip edilmediği üzerine bir başarım değerlendirmesi yapılmıştır. Görüntü ayırma işleminden sonra arka plan görüntüsünden ayrılan tümör görüntülerin başarım durumu analitik yöntemler kullanarak incelenmiştir. İlk aşamada TP, TN, FP ve FN değerleri ile bir doğruluk ölçümü yapılabileceği varsayılmıştı. Fakat yapılan araştırmalar sonucunda literatürde eşikleme işleminin başarım durumunu test eden bir analitik yöntemin henüz olmadığ görülmüștür. Ayrıștırma ișlemi sonunda $\mathrm{TP}, \mathrm{TN}, \mathrm{FP}$ ve FN piksellerinin sayılarak 
performansın bulunması, insan desteği gerektiren zor bir iştir. Bu durumda doktorlar tarafından görsel olarak yapılan başarım değerlendirmesinin yeterli olduğunu düşünmekteyiz. Sağlık bilişimi alanında yapılan çalışmaların doktorların vereceği kararlara destek oluğu veya sağlık personelini uyarıcı bir nitelikte olduğunu tekrar hatırlatmakta fayda olduğunu düşünmekteyiz.

Elde edilen MR görüntü setinde farklı türlerde tümörlerin ve lezyonların bulunduğu görülmüştür. Farklı türlerdeki anormal dokuların şekilsel renk yoğunluğu ile ilgili özelliklerin tespiti amaciyla konunun uzmanı doktorlar tarafindan yeniden incelenmesi gerekti. Alınan geri bildirimlerden sonra uygulamada kullanilan algoritmalar tekrar düzenlenerek sistemin daha doğru sonuçlar vermesi sağlanmıştır.

$\mathrm{Bu}$ çalışmada Markov Random Field algoritmasını kullanarak hastaların MR görüntülerindeki tümör belirlenir. Yapılan uygulamada Markov Random Field algoritması ile beyin tümörünün tespiti kolaylaştırılarak bu hastalığa karşı erkenden önlem alınabileceği görülmüştür.

Çalışma sonucunda tıbbi verilerin segmentasyonu konusunda MRF algoritmasının daha iyi olduğu keşif edilip, yeni algoritmalar denenerek farklı sonuçların elde edilebileceği gözlenmiştir. Eğer bir algoritma sonucu tutarsız buluyor ise ROI ile sonuç istenen alana odaklama yapılabileceği görülmüștür. Bu arada beyin tümörünün görüntüleme yöntemleri ile tespit edilmesinde farklı yol ve yöntemlerin geliştirilebileceği ifade edilmiştir.

Çalışma sonucunda tıbbi görüntülerin segmentasyonu konusunda MRF algoritmasının diğer yöntemlere göre daha iyi olduğu görülmüştür. Ayrıca görüntü üzerinde ROI yöntemi ile belirli bir bölge üzerinde çalışmanın daha başarılı sonuçlar verdiği görülmüștür.

\section{Teşekkür}

MR görüntülerinin elde edilebilmesi için resmi izni veren İzmir Kuzey Kamu Hastaneleri Birliği'ne, Karşıyaka Devlet Hastanesi Beyin ve Sinir Hastalıkları kliniğine teşekkürlerimizi arz ederiz. Resmi izinlerin alınmasında ve verilerin toplanmasinda bizlere yardimcl olan Mustafa Ege ŞEKER ve Mustafa Eray KILIÇ’a ayrica teşekkür ederiz.

\section{Kaynakça}

[1] Arzu, İ. L. Ç. E., Burcu TOTUR, and Türkan ÖZBAYIR. 2010.

"Evaluation of Patients With Brain Tumors According to International NANDA Nursing Diagnoses: Care Suggestions." Journal of Neurological Sciences, 27.2.

[2] Dicle, A., Baksi Şimşek, A., 2010. MD Anderson Beyin Tümörü Semptom Envanteri'nin Geçerlilik ve Güvenilirliği.

[3] Bauer, S., Wiest, R., Nolte, L. P., \& Reyes, M. 2013. A survey of MRIbased medical image analysis for brain tumor studies. Physics in medicine and biology, 58(13), R97.

[4] Gordillo, N., Montseny, E., \& Sobrevilla, P. (2013). State of the art survey on MRI brain tumor segmentation. Magnetic resonance imaging, 31,8:1426-1438.

[5] Fazli, S., Nadirkhanlou, P. 2013. A novel method for automatic segmentation of brain tumors in MRI images, arXiv preprint arXiv, 1312.7573.

[6] Gajanayake, G. M. N. R., Roshan Dharshana Yapa, B. Hewawithana. 2009. "Comparison of standard image segmentation methods for segmentation of brain tumors from 2D MR images." Industrial and Information Systems (ICIIS), 2009 
F. Bulut, İ. Kılıç, İ.F. İnce / Beyin Tümörü Tespitinde Görüntü Bölütleme Yöntemlerine Ait Başarımların Karşılaştırılması ve Analizi

International Conference on. IEEE. DOI:

0.1109/ICIINFS.2009.5429848

[7] Kurat, N., Ozkaya N. 2014. Automaticly extracting brain tumor from MR image, Signal Processing and Communications Applications Conference (SIU) on IEEE, 22nd. IEEE, 1532-1535. DOI: 10.1109/SIU.2014.6830533

[8] Havaei, M., Davy, A., Warde-Farley, D., Biard, A., Courville, A., Bengio, Y., ... \& Larochelle, H. 2017. Brain tumor segmentation with deep neural networks. Medical image analysis, 35: 18-31. DOI: 10.1016/j.media.2016.05.004

[9] Huang, Mengxing, Wenjiao Yu, and Donghai Zhu. 2012. "An improved image segmentation algorithm based on the Otsu method." Software Engineering, Artificial Intelligence, Networking and Parallel \& Distributed Computing (SNPD), 13th ACIS International Conference on. IEEE. DOI: 10.1109/SNPD.2012.26

[10] Zhou, Chenhang, et al. 2015. "A method of Two-Dimensional Otsu image threshold segmentation based on improved Firefly Algorithm." Cyber Technology in Automation, Control, and Intelligent Systems (CYBER), International Conference on IEEE. DOI: 10.1109/CYBER.2015.7288151

[11] Prema, V., M. Sivasubramanian, and S. Meenakshi. 2016. "Brain cancer feature extraction using otsu's thresholding segmentation." BRAIN 6.3.

[12] Liu, J., Zheng, J., Tang, Q., \& Jin, W. 2014. Minimum error thresholding segmentation algorithm based on 3d grayscale histogram. Mathematical Problems in Engineering, 2014.

[13] Bhandari, Ashish Kumar, et al. 2014. "Cuckoo search algorithm and wind driven optimization based study of satellite image segmentation for multilevel thresholding using Kapur's entropy." Expert Systems with Applications 41.7: 3538-3560. DOI: https://doi.org/10.1016/j.eswa.20 13.10.059

[14] Roy, P.K., Bhuiyan, A., Janke A., Desmond P.M., Wong. T.Y. 2015. Automatic white matter lesion segmentation using contrast enhanced FLAIR intensity and Markov Random Field, Computerized Medical Imaging and Graphics, 45: 102-111. DOI: https://doi.org/10.1016/j.compme dimag.2015.08.005

[15] Uzunbas, M.G., Chen C., Metaxas D., 2016. An efficient conditional random field approach for automatic and interactive neuron segmentation, Medical Image Analysis, 27: 31-44. DOI: 10.1016/j.media.2015.06.003

[16] Kutarnia, J., Pedersen, P. A 2015. Markov random field approach to group-wise registration / mosaicing with application to ultrasound, Medical Image Analysis, 24: 106-124. DOI: 10.1016/j.media.2015.05.011

[17] Otsu, N., 1975. A threshold selection method from gray-level histograms, Automatica, 11 (285-296), 23-27.

[18] Sezgin, M., Sankur, B. 2004. Survey over image thresholding techniques and quantitative performance evalution, Journal of Electronic Imaging, 13: 146-165. DOI: http://dx.doi.org/10.1117/1.1631 315

[19] Kapur, J. N., Sahoo, P. K., \& Wong, A. K. 1985. A new method for graylevel picture thresholding using the entropy of the histogram, Computer vision, graphics, and image processing, 29,3: 273-285. 
F. Bulut, İ. Kılıç, İ.F. İnce / Beyin Tümörü Tespitinde Görüntü Bölütleme Yöntemlerine Ait Başarımların Karşılaştırılması ve Analizi

[20] Kittler, J., Illingworth, J., 1986. Minimum Error Thresholding, Pattern recognition, 19: 41-47.

[21] Kilic, İ. and Kayacan. O. 2012. Physica A: Statistical Mechanics and its Applications, Generalized ICM for image segmentation based on Tsallis statistics, 20, 4899-4908.

[22] Zeng, M., Han, T., Meng, Q., Bai, Z., \& Liu, Z. 2012. Image thresholding based on edge information analysis,

In Image and Signal Processing (CISP)5th International Congress on IEEE, 1371-1375. DOI: 10.1109/CISP.2012.6469984

[23] FAWCETT, Tom. 2006. An introduction to ROC analysis. Pattern Recognition Letters, 27,8: 861-874.

DOI: https://doi.org/10.1016/j.patrec.2 005.10 .010 